\title{
Efficiency of Triple-SCoT Primer in Characterization of Genetic Diversity and Genotype-Specific Markers against SSR Fingerprint in Some Egyptian Barley Genotypes
}

\author{
Aziza A. Aboulila ${ }^{*}$, Mohamed Mansour ${ }^{2}$ \\ ${ }^{1}$ Genetics Department, Faculty of Agriculture, Kafrelsheikh University, Kafr El-Sheikh, Egypt \\ ${ }^{2}$ Barley Department, Field Crop Research Institute, Agricultural Research Center, Giza, Egypt \\ Email: *aziza.aboulila@agri.kfs.edu, *aa_aboulila@yahoo.com
}

How to cite this paper: Aboulila1, A.A. and Mansour, M. (2017) Efficiency of Triple-SCoT Primer in Characterization of Genetic Diversity and Genotype-Specific Markers against SSR Fingerprint in Some Egyptian Barley Genotypes. American Journal of Molecular Biology, 7, 123-137.

https://doi.org/10.4236/ajmb.2017.73010

Received: April 14, 2017

Accepted: June 10, 2017

Published: June 13, 2017

Copyright $\odot 2017$ by authors and Scientific Research Publishing Inc. This work is licensed under the Creative Commons Attribution International License (CC BY 4.0).

http://creativecommons.org/licenses/by/4.0/

\begin{abstract}
Ten Egyptian barley genotypes ( 2 commercial varieties and 8 breeding lines) were cultivated under normal condition at the Experimental Farm of Sakha Agricultural Research station and exposed to salinity stress condition at the Experimental Farm of El-hosainia plain Agricultural Research station, Elsharkia Governorate, Egypt, in an attempt to identify the relative salinity tolerant genotypes. A susceptibility index (SI) was used to estimate the relative stress loss because it accounted for variation in yield potential and stress intensity. Giza 123, Line-1, Line-5, Line-6 and Line-8 genotypes were considered as saline tolerant genotypes on the basis of their highly tolerance indices values. Barley genotypes were characterized by seven SSR markers and three SCoT primers in different combinations to discern the extent of genetic variation and develop a fingerprinting key. Normal SCoT reactions amplify single segments of DNA which are 15- to 19-mer long. A new strategy was used to increase SCoT potential in genetic diversity studies by using two and three different primer combinations per reaction. Amplification products scored a polymorphism percentage of $94.44 \%$ for Triple-SCoT and $90.91 \%$ for SSR, while the average no. of polymorphic fragments/primer was 17 and 7.14 in the two marker systems, respectively. On the other side, Triple-SCoT exhibited the highest average number of positive and negative genotype-specific markers. The cluster analysis of the studied genotypes using these different marker systems revealed four dendrograms varied in their topology. The dendrogram based on Triple-SCoT data exhibited the closest relationships to those illustrated by SSR dendrogram.
\end{abstract}

\section{Keywords}

Barley, Triple-SCoT, SSR, DNA Barcoding, Genetic Similarity 


\section{Introduction}

Barley (Hordeum vulgare L.) is the fourth most cultivated crop worldwide. Environmental stresses such as low water availability, salinity and mineral toxicity frequently affect plants in agricultural systems and represent major limitations to the yield and quality of barley and other crops. Salinity is a strong abiotic stress affecting crops in Egypt and worldwide. However, Egypt is one of the countries that suffer from severe salinity problems in some areas. About $30 \%$ of the cultivated area in Egypt and is already salinized [1]. Salinity adversely affects the growth and yield of crop plants by decreasing the availability of soil moisture, and also due to the toxicity effects of sodium ions at high concentrations to the plant [2].

Application of DNA fingerprinting was primarily used in plants for identification of genetic diversity, biodiversity protection or germplasm conservation and identifying markers associated with specific traits [3]. Molecular markers based on SSR (Simple Sequence Repeats) are powerful techniques because they are codominant, multi-allelic, easily scored and highly polymorphic, which can be used to identify and determine plant genomes or to evaluate the phylogenetic relationship among genotypes of barley [4] [5] [6]. However, a major drawback of microsatellite markers is the time and cost required to characterize them [7]. The molecular markers technologies continue to be improved with development of simpler protocols with greater reliability and lower cost. This makes them increasingly practical for routine applications to tropical or subtropical species for which very limited research resources are available.

Start codon targeted (SCoT) polymorphism; a simple and novel DNA marker technique, performed through PCR using single primer targeting the short consensus conserved region flanking the ATG translation initiation codon in plant genes. This has been validated through study on genetic diversity among rice varieties and marker segregation in rice backcross population [8]. There is an urgent need to develop more suitable and tightly linked markers for improved traits (molecular signature) and its further utilization in plant improvement and breeding programmes for exploitation of genetic resources for the sake of commercial and academic needs. Also, in this investigation we used two and three different primer combinations based SCoT (Double and Triple-SCoT, respectively) per single reaction as a new strategy to enhance SCoT efficiency for genetic diversity assessment and this is the first time for using this method in SCoT marker.

DNA barcoding, a relatively new concept, developed for providing rapid, accurate and automatable species identification using standardized DNA sequences as tags is being recognized as a powerful addition to the tools of the taxonomist [9]. In DNA barcoding, the unique nucleotide sequence patterns of small DNA fragments (400 - $800 \mathrm{bp}$ ) are used as specific reference collections to identify specimens and to discover overlooked species[10].

The purpose of this study was the molecular evaluation of some Egyptian barley genotypes (commercial cultivar and improved/selected lines) for salinity to- 
lerance by using SCoT and SSR markers. Also, comparison between Triple-SCoT (three primer based SCoT marker) and SSR techniques was an important aim of this study. This may provide rare diagnostic marker(s) and may help in defining genetic relationship among the genotypes.

\section{Material and Methods}

\subsection{Plant Material}

This study was carried out at the laboratory of molecular genetics, Genetics Department, Faculty of Agriculture, Kafrelsheikh University, Egypt and the Experimental Farm of Sakha Agricultural Research Station (ARC), Egypt, (normal condition) and the Experimental Farm at El-hosainia plain Agricultural Research station, Elsharkia Governorate, Egypt (saline soil condition) during the two successive seasons 2013/14 and 2014/15. Ten barley genotypes (two local varieties; Giza 123 and Giza 132 and eight breeding lines named as Line-1 to Line8) as presented in Table 1 were chosen from Sakha Agricultural Research Station (ARC), Egypt for the study based on their reputed differences in yield performance under normal and saline conditions.

\subsection{Tolerance Indices}

These indices were calculated as mentioned in previous studies as follow; stress susceptibility index (SSI) [11], mean productivity (MP) [12], stress tolerance index (STI) and geometric mean productivity (GMP) [13], yield index (YI) [14], yield stability index (YSI) [15] and tolerance (TOL) [16].

\subsection{DNA Extraction}

Total genomic DNA was extracted from fresh young leaves at tillering stage from $100-150 \mathrm{mg}$ by using Cetyl trimethyl ammonium bromide (CTAB)-based procedure for plants [17]. Quantity and quality of the extracted DNA samples were estimated by comparing band intensities against standard DNA ladder on $1.0 \%$ agarose gel. DNA samples were diluted to a final concentration of $40 \mathrm{ng} / \mu \mathrm{l}$ before PCR amplification.

\subsection{Primer Selection}

A preliminary experiment on 10 selected barley genotypes was carried out to se-

Table 1. Name and sequence of seven SSR primers used in this study.

\begin{tabular}{ccc}
\hline Primer name & Forward $\left(\mathbf{5}^{\prime} \rightarrow \mathbf{3}^{\prime}\right)$ & Reverse $\left(\mathbf{5}^{\prime} \rightarrow \mathbf{3}^{\prime}\right)$ \\
\hline SSR-1 & CCGTCGCCGTAGTAGAGAAG & TCCCGGTTATTTTAAGGCG \\
sSR-2 & CTCGTTTATTACCTACAGTACC & CTACCTCCTTTCTAGACCGATA \\
sSR-3 & CTGGCCATTAGTCCTTGG & GCTTGCGGCTCTGCTTAC \\
ssR-4 & GAGCTCCATCAGCCATTCAG & CTGAGTGCTGCTGCGACT \\
sSR-5 & CTACTTCTCCCCTTGTGTCG & TGTACCATCGCCAAATCTCC \\
SSR-6 & GATCCCCTCCGTCAAACAC & CCCTTCTCCTTTCCTCAACC \\
SSR-7 & CTCTTCACTCACTCACCATGG & ATCCATCTGGAGCAAGCAAC \\
\hline
\end{tabular}


lect the most suitable primer types for identification of genetic diversity. Three SCoT primers (were used in different combinations as single, double and triple) and seven SSR primers were screened for repeatability, scorability, and their ability to distinguish the different genotypes. These primers were employed for genotypic identification and phylogenetic analysis for studying the relationships.

\subsection{Amplification Conditions and Fragment Analysis}

\subsubsection{SCoT Analysis}

DNA samples were subjected to SCoT assay, using 3 (14 - 19 mer) primers and primer combinations (iNtRON Biotechnology, Inc, Korea) with GC content of $60 \%$ (Table 3). Amplification reactions were performed in $20 \mu \mathrm{l}$ volume containing $1 \mu \mathrm{l}$ of template DNA (40 ng/ $\mu \mathrm{l}), 1.0 \mu \mathrm{l}$ of primer $(10 \mathrm{pmol} / \mu \mathrm{l}), 10 \mu \mathrm{l} 2 \mathrm{X}$ PCR Master mix solution [(i-Taq $\left.{ }^{\mathrm{TM}}\right)$ iNtRON Biotechnology] and $8 \mu \mathrm{l}$ of sterile $\mathrm{ddH} 2 \mathrm{O}$. The reaction mixtures were overlaid with $20 \mu \mathrm{l}$ of mineral oil per sample. The PCR amplification was performed on a thermal cycler (Perkin Emer Cetus) programmed for $5 \mathrm{~min}$. at $94^{\circ} \mathrm{C}$ followed by 35 cycles of $1 \mathrm{~min}$. at $94^{\circ} \mathrm{C}, 1$ min. at $50^{\circ} \mathrm{C}$ and $1.5 \mathrm{~min}$. at $72^{\circ} \mathrm{C}$ and a final stage of $7 \mathrm{~min}$. at $72^{\circ} \mathrm{C}$ (one cycle) then at $4^{\circ} \mathrm{C}$ for keeping until use.

\subsubsection{Microsatellite (SSR) Analysis}

The flanking regions of the microsatellite, alternatively called simple sequence repeats, are generally conserved among genotypes of the same species. Therefore, PCR primers to the flanking regions are used to amplify SSR-containing DNA fragments. A total of 7 microsatellite specific primer pairs (SSR-1 to SSR7) (iNtRON Biotechnology, Inc, Korea) (Table 1) were tested. PCR reaction was performed as previously described [18].

\subsection{Detection of PCR Products}

Amplification products were separated by horizontal gel electrophoresis unit using 1.5\% agarose gel. Bands were detected on Benchtop UV-transilliminator and photographed using photo Doc-It ${ }^{\mathrm{TM}}$ imaging system. The molecular size of the amplified products was determined against O'GeneRuler DNA Ladder Mix ready-to-use (Thermo Scientific).

\subsection{Data Analysis}

DNA banding patterns generated from SCoT and SSR techniques were analyzed by GelAnalyzer 3 program. The presence (1) or absence (0) of bands was scored. By comparing the banding patterns of genotypes (cultivars) for a specific primer, genotype-specific bands (positive or negative unique bands) were identified. The binary data generated were used to estimate the levels of polymorphism which calculated by dividing the polymorphic bands/the total number of scored bands. From this matrix, Jacard's similarity coefficient between paris of genotypes was calculated using Nei \& Li coefficients [19] by computational package MVSP 3.1. The distance coefficients were used to construct a dendrogram using the unweighted pair grouped method arithmetic average (UPGMA) to determine the 
genetic diversity and relationships among the used genotypes.

\section{Results}

\subsection{Salinity Susceptibility Index (SSI)}

A susceptibility index (SI), which provides a measure of stress tolerance based on minimization of yield loss under stress as compared to optimum conditions, rather than on yield level under stress, has been used to characterize the relative tolerance of wheat genotypes [11]. This index was used to estimate the relative stress loss because it accounted for variation in yield potential and stress intensity. This index could be estimated based on many traits. Lower stress susceptibility index than unity $(\mathrm{SI}<1)$ is synonymous to high stress tolerance, while higher stress susceptibility index (SI $>1$ ) means higher stress sensitivity. Data in Table 2 indicated that, Giza 123, Line-1, Line-5, Line- 6 and Line- 8 genotypes were considered as tolerant genotypes based on most tolerance indices for possessed high values for MP, STI, GMP, YI and YSI and also SSI was less than one, in addition to low values of TOL, revealing that these parents were more tolerant to salinity stress.

To assess the genetic variability and relationships among the 10 barley genotypes, 14 different primers and primers combinations were used; they revealed polymorphic patterns which will be used in further analysis.

\subsection{Marker Informativeness}

\subsubsection{Polymorphism as Detected by SCoT Analysis}

In the present study, three SCoT primers (SCoT-7, SCoT-8 and SCoT-9) in single, double and triple combinations as shown in Table 3 were used to amplify the ten barley genotypes. These primers yielded a total of 94 bands (38, 38 and 18) in the three marker systems (single, double and triple-SCoT, respectively),

Table 2. Tolerance indices for grain yield characters of the ten barley genotypes as the average of the two seasons under stress conditions.

\begin{tabular}{cccccccc}
\hline Genotypes & SSI & MP & STI & GMP & YI & YSI & TOL \\
\hline Giza 123 & 0.83 & 1885.59 & 1012.42 & 1875.28 & 1133.34 & 0.81 & 393.82 \\
Giza 132 & 0.91 & 1672.44 & 897.98 & 1661.26 & 992.87 & 0.79 & 386.12 \\
Line-1 & 0.96 & 1735.09 & 931.62 & 1721.79 & 1020.59 & 0.78 & 428.82 \\
Line-2 & 1.04 & 1767.85 & 949.21 & 1751.80 & 1026.98 & 0.76 & 475.30 \\
Line-3 & 1.32 & 1777.46 & 954.37 & 1749.23 & 981.16 & 0.70 & 631.08 \\
Line-4 & 0.97 & 1640.94 & 881.07 & 1628.27 & 964.68 & 0.78 & 407.12 \\
Line-5 & 0.37 & 1692.60 & 908.80 & 1690.94 & 1085.70 & 0.92 & 149.80 \\
Line-6 & 0.70 & 1910.09 & 1025.58 & 1902.91 & 1170.93 & 0.84 & 330.82 \\
Line-7 & 1.60 & 1674.75 & 899.22 & 1632.74 & 873.83 & 0.64 & 745.50 \\
Line-8 & 0.72 & 1938.09 & 1040.61 & 1930.41 & 1185.02 & 0.84 & 344.82 \\
\hline
\end{tabular}

SSI = Salinity susceptibility index, MP = mean productivity, STI = stress tolerance index, GMP = geometric mean productivity, YI = yield index, YSI = yield stability index, TOL = tolerance. 
out of them $79(84.04 \%)$ were found to be polymorphic with an average of 11.29 bands/primer combination as shown in Table 3 and Figure 1 . While, the total percentages of polymorphism were $73.68,89.47$ and $94.44 \%$ in the three SCoT
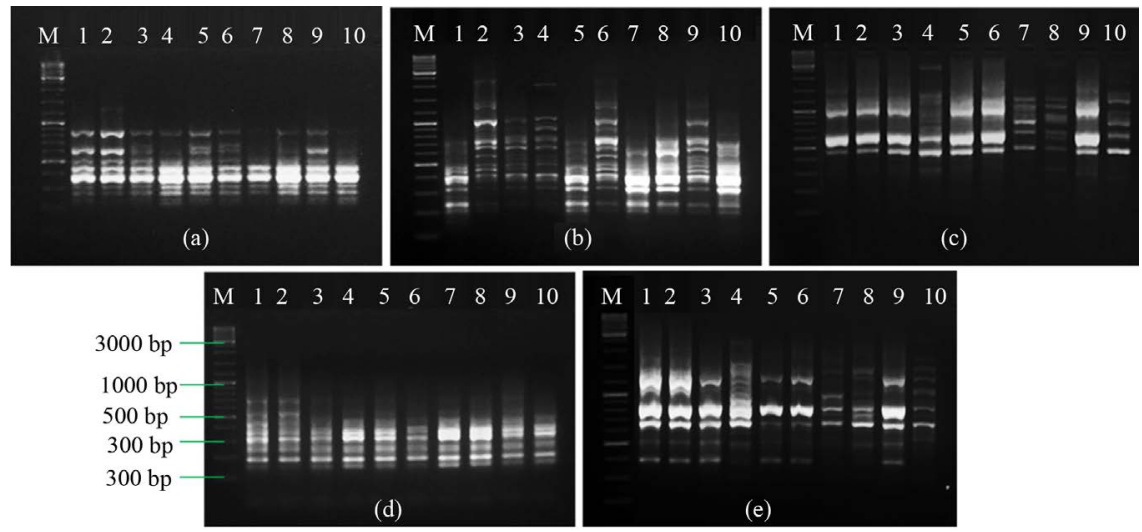

Figure 1. SCoT fingerprints of ten barley genotypes generated by (a) SCoT-8, (b) SCoT- 9 , (c) Double SCoT (SCoT-7 + SCoT-9), (d) Double SCoT (SCoT-8 + SCoT-9) and (e) Triple-SCoT (SCoT-7 + SCoT-8 + SCoT-9). M is 100 bp DNA Ladder, 1: Giza 123, 2: Giza 132, 3: Line-1, 4: Line-2, 5: Line-3, 6: Line-4, 7: Line-5, 8: Line-6, 9: Line-7 and 10: Line-8.

Table 3. Primer name, sequence, molecular size range, bands number and percentage of polymorphism as detected by SCoT markers.

\begin{tabular}{|c|c|c|c|c|c|c|c|c|}
\hline \multirow{2}{*}{$\begin{array}{l}\text { Molecular marker } \\
\text { technique }\end{array}$} & \multirow{2}{*}{$\begin{array}{l}\text { Primer } \\
\text { Name }\end{array}$} & \multirow{2}{*}{$\begin{array}{l}\text { Primer sequence } \\
\qquad\left(5^{\prime} \rightarrow 3^{\prime}\right)\end{array}$} & \multirow{2}{*}{$\begin{array}{l}\text { Molecular size } \\
\text { range (bp) }\end{array}$} & \multirow{2}{*}{ TAB } & \multirow{2}{*}{ PB } & \multirow{2}{*}{$\mathrm{P}(\%)$} & \multicolumn{2}{|c|}{ TSM } \\
\hline & & & & & & & No. & Genotype \\
\hline \multirow{3}{*}{ Single-SCoT } & SCoT-7 & ACAATGGCTACCACTGAC & $275-1346$ & 9 & 5 & 55.56 & 3 & $\begin{array}{l}\text { Giza } 123(1) \\
\text { Giza } 132(2)\end{array}$ \\
\hline & SCoT-8 & ACAATGGCTACCACTGAG & $233-1279$ & 10 & 5 & 50.00 & 1 & Giza 132 \\
\hline & SCoT-9 & ACAATGGCTACCACTGCC & $164-2350$ & 19 & 18 & 94.74 & 4 & $\begin{array}{c}\text { Giza } 132(1) \\
\text { Line-3 (1) } \\
\text { Line-7 (2) }\end{array}$ \\
\hline Total & & & & 38 & 28 & 73.68 & 8 & \\
\hline \multirow{3}{*}{ Double-SCoT } & $\begin{array}{l}\text { SCoT-7 } \\
+ \\
\text { SCoT-8 }\end{array}$ & $\begin{array}{l}\text { ACAATGGCTACCACTGAC } \\
\text { ACAATGGCTACCACTGAG }\end{array}$ & $223-787$ & 9 & 9 & 100.00 & 6 & $\begin{array}{c}\text { Giza } 132(5) \\
\text { Line-7 (1) }\end{array}$ \\
\hline & $\begin{array}{l}\text { SCoT-7 } \\
+ \\
\text { SCoT-9 }\end{array}$ & $\begin{array}{l}\text { ACAATGGCTACCACTGAC } \\
\text { ACAATGGCTACCACTGCC }\end{array}$ & $259-3004$ & 20 & 20 & 100.00 & 6 & $\begin{array}{l}\text { Line-2 (2) } \\
\text { Line-5 (1) } \\
\text { Line-6 (1) } \\
\text { Line-7 (2) }\end{array}$ \\
\hline & $\begin{array}{l}\text { SCoT- } 8 \\
+ \\
\text { SCoT-9 }\end{array}$ & $\begin{array}{l}\text { ACAATGGCTACCACTGAG } \\
\text { ACAATGGCTACCACTGCC }\end{array}$ & $159-720$ & 9 & 5 & 55.56 & 1 & Line-4 \\
\hline Total & & & & 38 & 34 & 89.47 & 13 & \\
\hline Triple-SCoT & $\begin{array}{c}\text { SCoT-7 } \\
+ \\
\text { SCoT-8 } \\
+ \\
+ \\
\text { SCoT-9 }\end{array}$ & $\begin{array}{l}\text { ACAATGGCTACCACTGAC } \\
\text { ACAATGGCTACCACTGAG } \\
\text { ACAATGGCTACCACTGCC }\end{array}$ & $431-3043$ & 18 & 17 & 94.44 & 8 & $\begin{array}{l}\text { Line-2 (3) } \\
\text { Line-5 (1) } \\
\text { Line-8 (4) }\end{array}$ \\
\hline Grand total & & & & 94 & 79 & & 29 & \\
\hline
\end{tabular}

TAB = Total number of amplified bands, $\mathrm{PB}=$ number of polymorphic bands, $\mathrm{P}(\%)=$ polymorphism percentage and TSM $=$ Total no. of genotype-specific markers including presence or absence of a band in a specific genotype. 
systems (single, double and triple-SCoT, respectively) indicating that TripleSCoT showed the highest percentage of polymorphism (94.44\%).

From the results summarized in Table 3, it was noticed that Triple-SCoT technique proved to be the best one in comparison with the other two SCoT combination techniques (single and double-SCoT) while it gave the highest polymorphism percentage value (94.44\%) and also the highest total genotype-specific markers (TSM) value (8) as presented in Table 3.

\subsubsection{Polymorphism as Detected by SSR Analysis}

Data in Table 4 and Figure 2 were obtained from 7 microsatellite primer pairs which were screened against the ten barley genotypes in an attempt to detect polymorphic markers. The seven SSR primer pairs exhibited 55 major SSR alleles and the number of polymorphic alleles was 50 , representing a polymorphism percentage of $90.91 \%$. The total number of alleles per primer ranged from six (SSR-2, SSR-5 and SSR-7) to eleven (SSR-4 and SSR-6). The number of polymorphic alleles generated by individual primer pair ranged from six to ten. The average of total alleles per primer was 7.86, while it was 7.14 for polymorphic al leles. Also, the seven SSR primer pairs exhibited 28 loci, ranged from 2 in SSR-7
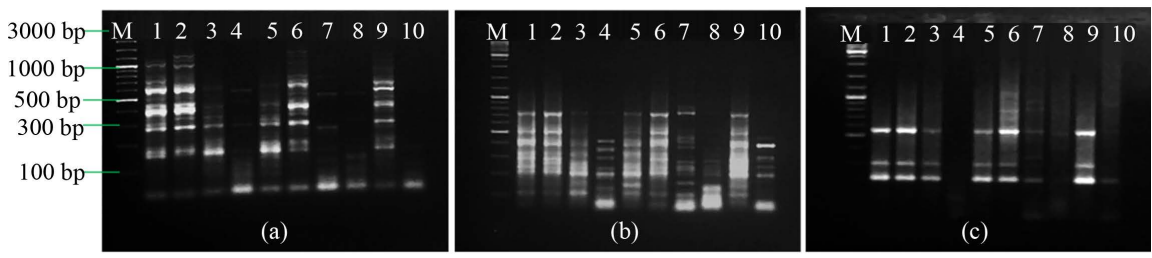

Figure 2. SSR fingerprints of the ten barley genotypes generated by (a) SSR-4, (b) SSR-6 and (c) SSR-7. $M$ is 100 bp DNA Ladder, 1: Giza 123, 2: Giza 132, 3: Line-1, 4: Line-2, 5: Line-3, 6: Line-4, 7: Line-5, 8: Line-6, 9: Line-7 and 10: Line-8.

Table 4. Total number of allels, polymorphic allels, percentage of polymorphism, loci number and size detected by SSR markers.

\begin{tabular}{|c|c|c|c|c|c|c|c|c|}
\hline \multirow[b]{2}{*}{ Primer Name } & \multirow[b]{2}{*}{ Repeat motif } & \multirow{2}{*}{\multicolumn{2}{|c|}{ Number of alleles }} & \multirow{2}{*}{$\begin{array}{c}P \\
(\%)\end{array}$} & \multirow[b]{2}{*}{ No. of loci } & \multirow[b]{2}{*}{ Size of loci (bp) } & \multicolumn{2}{|c|}{ TSM } \\
\hline & & & & & & & No. & Genotype \\
\hline SSR-1 & $(\mathrm{GA}) 17$ & 8 & 7 & 87.5 & 4 & $82 \& 346 \& 513 \& 791$ & 0 & -- \\
\hline SSR-2 & (CT) 17 & 6 & 6 & 100 & 4 & $152 \& 231 \& 366 \& 537$ & 0 & -- \\
\hline SSR-3 & (CA)6(GA)36 & 7 & 6 & 85.7 & 4 & $145 \& 258 \& 576 \& 889$ & 2 & Line-8 \\
\hline SSR-4 & $(\mathrm{CT}) 20$ & 11 & 9 & 81.82 & 6 & $87 \& 215 \& 356 \& 457 \& 743 \& 1322$ & 1 & Line-8 \\
\hline SSR-5 & $\mathrm{C} 9(\mathrm{CT}) 8$ & 6 & 6 & 100 & 3 & $232 \& 462 \& 1151$ & 3 & Giza 132 \\
\hline SSR-6 & $(\mathrm{GAT}) 8$ & 11 & 10 & 90.91 & 5 & $140 \& 219 \& 308 \& 482 \& 737$ & 4 & $\begin{array}{l}\text { Line-5 (1) } \\
\text { Line-6 (2) } \\
\text { Line-8 (1) }\end{array}$ \\
\hline SSR-7 & (TC) 15 & 6 & 6 & 100 & 2 & $277 \& 1034$ & 2 & $\begin{array}{l}\text { Line-4 (1) } \\
\text { Line-5 (1) }\end{array}$ \\
\hline Total & & 55 & 50 & 90.91 & 28 & & 12 & \\
\hline Average & & 7.86 & 7.14 & & & & 1.7 & \\
\hline
\end{tabular}

$\mathbf{T}=$ Total number of allels, $\mathbf{P}=$ number of polymorphic allels, $\mathbf{P}(\%)=$ polymorphism percentage and $\mathbf{T S M}=$ Total no. of genotype-specific markers including presence or absence of a band in a specific genotype. 
to 6 in SSR-4. The total number of genotype-specific markers per primer ranged from 0 to 4 .

From the above mentioned results, it was of great interest to make comparison between Triple-SCoT technique and the specific powerful technique (SSR) to estimate the phylogenetic relationships among the used barley genotypes.

\subsection{Suitability of SCoT and SSR Markers in Barcoding and Identification of Genotype-Specific Markers}

The randomly primer PCR approach beside specific primers (SSR) facilitated molecular distinction of barley genotypes as well as provided some genotypespecific markers too. The average number of amplified fragments and genotype specific markers are presented in Table 5. As presented in Figure 3 eight genotype-specific markers were amplified using Triple-SCoT marker (3) positives in Line- 2 , one positive in Line- 5 and 3 positives and one negative in Line- 8 genotypes), the highest number (4) was recorded by Line- 8 genotype (Figure 3 ). On the other hand, the seven SSR primers scored 55 amplified fragments, out of them 12 fragments were genotype-specific markers with an average of 1.71 fragments per primer (Table 4). Data of DNA barcoding shown in Figure 3 showed also that the highest number of genotype-specific markers (4) (one positive marker by SSR-3 and 3 negatives recorded by SSR-3, SSR-4 and SSR-6) were also recorded by Line- 8 genotype which generated the highest number of genotype-specific markers in the Triple-SCoT analysis.

\subsection{Phylogenetic Relationships among Ten Barley Genotype}

In Triple-SCoT analysis the highest genetic similarity value (1.0) was recorded

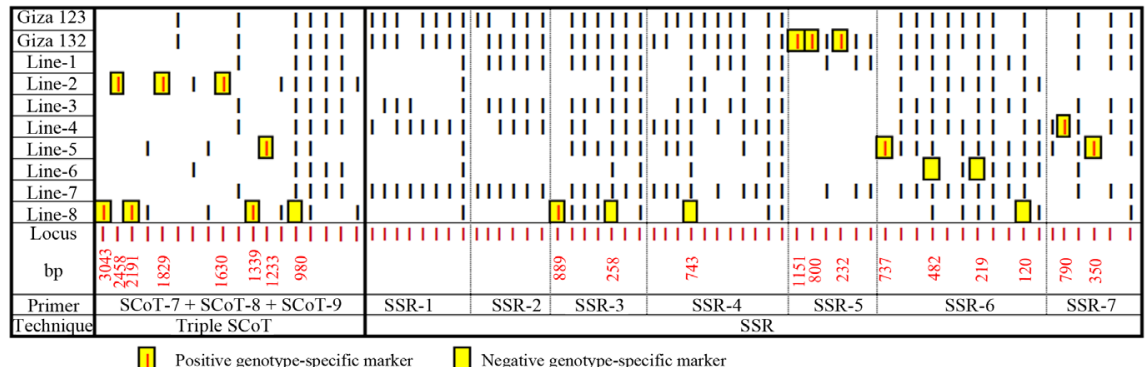

Figure 3. DNA-barcoding representation of Triple-SCoT and SSR fingerprints of the ten barley genotypes according to Adhikari et al. (2015).

Table 5. Distribution of amplified fragments in the ten barley genotypes using TripleSCoT and SSR markers.

\begin{tabular}{ccc}
\hline Parameters & Triple-SCoT & SSR \\
\hline Total number of amplified fragments & 18 & 55 \\
Average No. of polymorphic fragments per primer & 17 & 7.14 \\
Percentage of total polymorphic loci & 94.44 & 90.91 \\
Size range of amplified fragments (bp) & $431-3043$ & $82-1322$ \\
Average No. of genotype-specific markers per primer & 8 & 1.71 \\
\hline
\end{tabular}


between Line- 1 and each of lines-3, 4 and 7, Line- 3 and each of lines 4 and 7 and between Line-4 and Line-7 (Table 6). While, the lowest genetic similarity value (0.143) was detected between Giza 132 and Line-8 genotypes.

Also, genetic similarity was calculated for the seven SSR primers as presented in Table 7. The maximum value of similarity $(0.886)$ was observed between Giza 132 and Line-7 and the minimum similarity value $(0.357)$ was recorded between Giza 132 and Line-6 genotypes.

The dendrogram generated by UPGMA cluster analysis of the data produced according to Triple-SCoT analysis (Figure 4) presented two main clusters divided into four groups, the first cluster contained the two genotypes Line- 5 and Line-8 (group I), while, in the second cluster Giza 123 and Giza 132 were located at the same distance. Also, Line-1, Line-3, Line- 4 and Line-7 were located at the same distance and they showed the highest genetic similarity (100\%) as shown above in Table 6.

Table 6. Jaccard's similarity matrix of the ten barley genotypes according to Triple-SCoT analysis.

\begin{tabular}{|c|c|c|c|c|c|c|c|c|c|c|}
\hline Genotypes & Giza 123 & Giza 132 & Line-1 & Line-2 & Line-3 & Line-4 & Line-5 & Line-6 & Line-7 & Line- 8 \\
\hline Giza 123 & 1 & & & & & & & & & \\
\hline Giza 132 & 1 & 1 & & & & & & & & \\
\hline Line-1 & 0.909 & 0.909 & 1 & & & & & & & \\
\hline Line-2 & 0.5 & 0.5 & 0.533 & 1 & & & & & & \\
\hline Line-3 & 0.909 & 0.909 & 1 & 0.533 & 1 & & & & & \\
\hline Line-4 & 0.909 & 0.909 & 1 & 0.533 & 1 & 1 & & & & \\
\hline Line-5 & 0.364 & 0.364 & 0.4 & 0.267 & 0.4 & 0.4 & 1 & & & \\
\hline Line-6 & 0.727 & 0.727 & 0.8 & 0.667 & 0.8 & 0.8 & 0.4 & 1 & & \\
\hline Line-7 & 0.909 & 0.909 & 1 & 0.533 & 1 & 1 & 0.4 & 0.8 & 1 & \\
\hline Line-8 & 0.143 & 0.143 & 0.154 & 0.333 & 0.154 & 0.154 & 0.462 & 0.154 & 0.154 & 1 \\
\hline
\end{tabular}

Table 7. Jaccard's similarity matrix of the barley genotypes according to SSR analysis.

\begin{tabular}{|c|c|c|c|c|c|c|c|c|c|c|}
\hline Genotypes & Giza 123 & Giza 132 & Line-1 & Line-2 & Line-3 & Line-4 & Line-5 & Line- 6 & Line-7 & Line-8 \\
\hline Giza 123 & 1 & & & & & & & & & \\
\hline Giza 132 & 0.878 & 1 & & & & & & & & \\
\hline Line-1 & 0.771 & 0.816 & 1 & & & & & & & \\
\hline Line-2 & 0.582 & 0.525 & 0.571 & 1 & & & & & & \\
\hline Line-3 & 0.845 & 0.779 & 0.862 & 0.600 & 1 & & & & & \\
\hline Line-4 & 0.831 & 0.795 & 0.704 & 0.571 & 0.750 & 1 & & & & \\
\hline Line-5 & 0.677 & 0.592 & 0.678 & 0.682 & 0.700 & 0.697 & 1 & & & \\
\hline Line- 6 & 0.400 & 0.357 & 0.455 & 0.690 & 0.444 & 0.431 & 0.615 & 1 & & \\
\hline Line-7 & 0.878 & 0.886 & 0.816 & 0.492 & 0.805 & 0.867 & 0.648 & 0.393 & 1 & \\
\hline Line-8 & 0.462 & 0.414 & 0.478 & 0.581 & 0.468 & 0.453 & 0.634 & 0.538 & 0.414 & 1 \\
\hline
\end{tabular}


On the other side, a dendrogram derived from UPGMA cluster analysis based on SSR data showed that cluster analysis separated the genotypes into two clusters at 0.497 similarities (Figure 5). The first group comprised three genotypes only (Line-2, Line-6 and Line-8) while the other seven genotypes formed the second cluster. As the results of Triple-SCoT analysis, Line-7, Line-4, Line-1, Line-3, Giza 132 and Giza 123 were the nearest similar genotypes and located together.

\section{Discussion}

Genotypes with low SSI values (less than 1) can be considered to be salinity tolerant [20], because they exhibited smaller yield reduction under stress compared with normal condition than the means of all genotypes. However, the low SSI values may not necessarily give a good indication of salinity tolerance of genotype. Low SSI estimates of a variety could be as a result of lack of yield production under normal conditions rather than an indication of its ability to tolerate salinity.

DNA fingerprinting is an important tool for characterization of germplasm and establishment of the identity of varieties/hybrids/parental sources in breeding program. SCoT primers, despite having certain disadvantages (dominant nature and stringent optimization of assay), can produce multilocus profiles

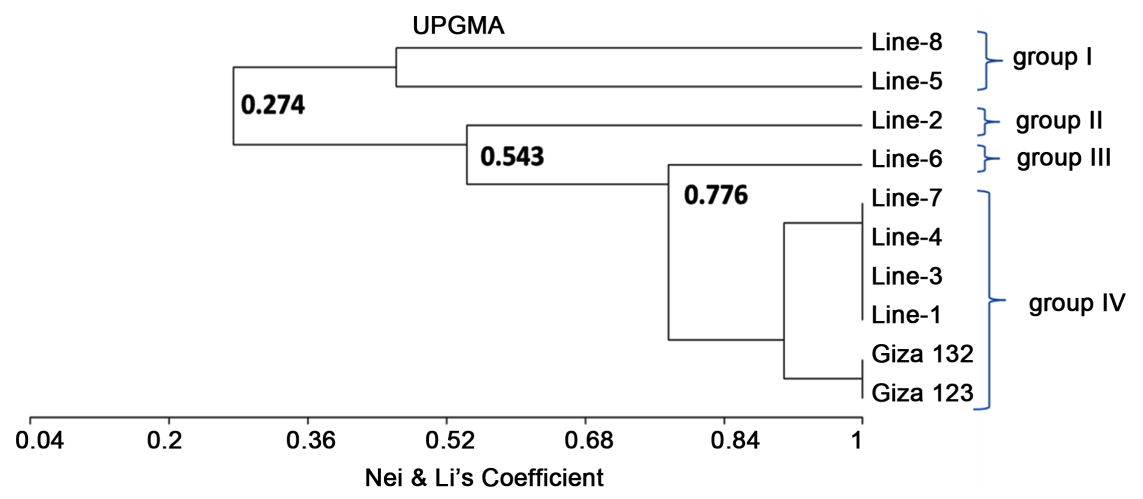

Figure 4. Hierarchical cluster analysis of the ten barley genortpes based on variations of Triple-SCoT patterns.

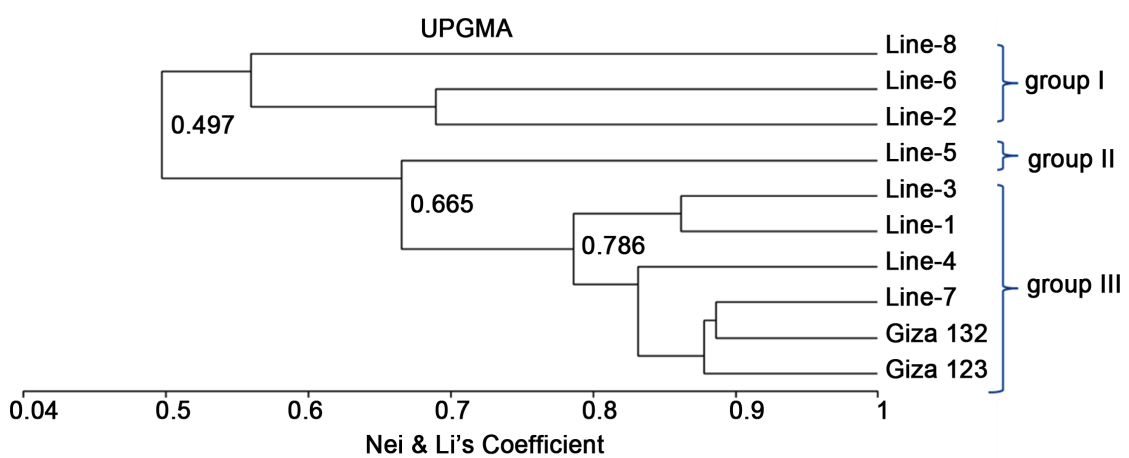

Figure 5. Hierarchical cluster analysis of the ten barley genortpes based on variations of SSR patterns. 
widely scanning the genome even in the absence of any prior genetic/sequence information. Therefore, in the present investigation, we employed SCoT marker with different combinations beside SSR marker to evaluate ten barley genotypes, to determine the molecular relationships among them, and to develop a fingerprinting key (molecular barcode) for commercial varieties and produced lines.

\subsection{Evaluation of SCoT and SSR Markers}

The 14 primer and primer combinations evaluated in the ten barley genotypes revealed high levels of diversity, detecting a total of 94 and 55 amplified fragments, 79 and 50 of them were polymorphic, averaging 11.29 and 7.14 polymorphic amplified fragments per primer for SCoT and SSR analyses, respectively.

The percentage of polymorphic bands was higher for Triple-SCoT (94.44\%) than for SSR (90.91\%). The average number of polymorphic amplification products obtained with SSR (7.14) was fewer than that of Triple-SCoT (17) as shown in Table 5. Therefore, both Triple-SCoT and SSR markers were the most efficient marker systems depending on their capacity to reveal several informative bands in a single amplification.

In the present study, di and tri nucleotide SSR motifs CT, TC, GA and GAT were used. Out of these, CT and GAT motifs produced the maximum scorable loci (Table 4), thus revealing more coverage of genome indicating that the microsatellites content of repetitive motifs $(\mathrm{CT})_{\mathrm{n}}$ and (GAT)n are more frequent than the repetitive motif targeted by the other SSR primers in barley. Also, SSR motifs CT and TC showed the maximum percentage of polymorphism (100\%). The above observations were in conformity with previous studies on Swertia chirayita [21] and on Gerbera [22].

\subsection{Relationships among Barley Genotypes}

Although major emphasis of this work was to generate DNA profiles of the genotypes, the marker data were also used to study genetic relationships among barley genotypes. The ten genotypes were divided into two clusters based on each of Triple-SCoT and SSR markers. The dendrogram showed high similarity between the trees results from Triple-SCoT and SSR primers. Line-8 genotype proved to be the best one, while it scored the highest number (4) of genotypespecific markers in both Triple-SCoT and SSR primers. This genotype (Line-8) with Giza 123 genotype proved to be the best barley tolerant genotypes as indicated by field experiment. In order to establish genetic relationships between the salinity tolerant genotypes, genetic similarity was calculated using Jaccard's similarity coefficient, which ranged from $14.3 \%$ to $100 \%$ and $35.7 \%$ to $88.6 \%$ for Triple-SCoT and SSR, respectively. These values were lower than those previously reported on the basis of SSRs (60.5 to 93.9\%) between Egyptian and ICARDA barley genotypes [18]. This is probably because of unequal distribution of SSR motifs throughout the genome in the form of clusters could not represent the entire genome well [23]. In the two commercial varieties (Giza 123 and Giza 
132), higher genetic similarity was observed among the two cultivars, indicating that both barley genotypes are closely related to each other and sharing the common genetic pool. These results agree with Triple-SCoT similarity. These results confirmed the result obtained by SSR analysis published in previous study [24], indicating the wide genetic diversity among them.

The higher genotypic variation observed in the studied barley genotypes might be due to the considerable chemotypic (largely quantitative) diversity [25] [26]. Similar anomalies in cluster analysis were also observed [18] who examined genomic and expressed molecular diversity of barley genotypes through SCoT and SSR analysis. Thus, phylogenetic studies revealed tight groupings among the barley genotypes with some incongruities in position of genotypes. This inconsistency between the molecular and chemotypic variation observed among the cultivars in the present study suggests that genotype and environment interactions also led to the diversification of chemical constituents, rather than genotypic differences [27] [28].

The differences found among the dendrograms generated by Triple-SCoT and SSRs could be partially explained by the different number of PCR products analysed reinforcing again the importance of the number of loci and their coverage of the overall genome, in obtaining reliable estimates of genetic relationships among barley cultivars. Similar results were observed also in barley [4] [29].

\subsection{Suitability of SCoT and SSR markers in barcoding}

The most important features of a DNA barcode are its universality, specificity on variation and easiness on employment. This means that the gene segment used as barcode should have high variation between species, but should be conserved within the species so that the intraspecific variation will be insignificant [30] [31]. In this respect, SCoT marker was easy to apply, rapid, cost-not effective, reproducible and highly discriminating. In this report, we have successfully developed genotype-specific molecular markers, which might contain some important gene sequences that could be used for the development of molecular barcodes for exploitation of genetic resources.

With increasing ease and speed of DNA sequencing alongside decreasing costs, DNA barcoding will facilitate rapid and large-scale biodiversity surveys, both for inventory purposes and ecological studies. These could be performed without presorting of samples or the necessity for taxonomists to devote their time to highly repetitive identification rather than additional scientific research.

\section{Conclusion}

To our best knowledge, this is the first report of detecting molecular variations and relationships of barley genotypes using Triple-SCoT markers. This study demonstrates that these markers are powerful tool for generating fingerprinting keys and have the potential to identify genotype-specific markers for barley. The identification of genotype-specific markers and the generation of fingerprinting keys for salinity tolerance are important resources for the breeding and man- 
agement of barley germplasm in comparison with the traditional breeding which needs long time and more cost.

\section{References}

[1] Noaman, M.M. (2008) Barley Development in Egypt. Proceedings of the 10 th International Barley Genetics Symposium, Alexandria, 5-10 April 2008.

[2] Munns, R. and Tester, M. (2008) Mechanisms of Salinity Tolerance. Annual Review of Plant Biology, 59, 651-681.

https://doi.org/10.1146/annurev.arplant.59.032607.092911

[3] Khanam, S., Sham, A.J., Bennetgen, L. and Mohammed, A.M.A. (2012) Analysis of Molecular Marker-Based Characterization and Genetic Variation in Date Palm (Phoenixdacty lifera L.). Australian Journal of Crop Science, 6, 1236-1244.

[4] Fernández, M.E., Figueiras, A.M. and Benito, C. (2002) The Use of ISSR and RAPD Markers for Detecting DNA Polymorphism, Genotype Identification and Genetic Diversity among Barley Cultivars with Known Origin. Theoretical and Applied Genetics, 104, 845-851. https://doi.org/10.1007/s00122-001-0848-2

[5] Saker, M.M, Nachtigall, M. and Kuehne, T.A. (2005) Comparative Assessment of DNA Fingerprinting by RAPD, SSR and AFLP in Genetic Analysis of Some Barley Genotypes. Egyptian Journal of Genetics and Cytology, 97, 81-97.

[6] Maniruzzaman, M. (2014) Polymorphism Study in Barley (Hordeum Vulgare) Genotypes Using Microsatellite (SSR) Markers. Bangladesh Journal of Agricultural Research, 39, 33-45.

[7] Fisher, P.J., Gardner, R.C. and Richardson, T.E. (1996) Single Locus Microsatellites Isolated Using 5’ Anchored PCR. Nucleic Acids Research, 24, 4369-4371.

https://doi.org/10.1093/nar/24.21.4369

[8] Collard, B.C. and Mackill, D.J. (2009) Start Codon Targeted (SCoT) Polymorphism: A Simple Novel DNA Marker Technique for Generating Gene-Targeted Markers in Plants. Plant Molecular Biology Reporter, 27, 86-93.

https://doi.org/10.1007/s11105-008-0060-5

[9] Hebert, P.D.N. and Gregory, T.R. (2005) The Promise of DNA Barcoding for Taxonomy. Systematic Biology, 54, 852-859. https://doi.org/10.1080/10635150500354886

[10] Kress, J.W., Wurdack, K.J., Zimmer, E.A., Weigt, L.A. and Janzen, D.H. (2005) Use of DNA Barcodes to Identify Flowering Plants. Proceedings of the National Academy of Sciences, 102, 8369-8374. https://doi.org/10.1073/pnas.0503123102

[11] Fischer, R.A. and Maurer, R. (1978) Drought Resistance in Spring Wheat Cultivars. I. Grain Yield Response. Australian Journal of Agricultural Research, 29, 897-907. https://doi.org/10.1071/AR9780897

[12] Hossain, A.B.S., Sears, A.G., Cox, T.S. and Paulsen, G.M. (1990) Desiccation Tolerance and Its Relationship to Assimilate Partitioning in Winter Wheat. Crop Science, 30, 622-627. https://doi.org/10.2135/cropsci1990.0011183X003000030030x

[13] Fernandez, G.C.J. (1992) Effective Selection Criteria for Assessing Plant Stress Tolerance. Proceedings of on the Symposium Taiwan, 25, 257-270.

[14] Gavuzzi, P., Rizza, F., Palumbo, M., Campaline, R.G., Ricciardi, G.L. and Borghi, B. (1997) Evaluation of Field and Laboratory Predictors of Drought and Heat Tolerance in Winter Cereals. Canadian Journal of Plant Science, 77, 523-531. https://doi.org/10.4141/P96-130

[15] Bouslama, M. and Schapaugh, W.T. (1984) Stress Tolerance in Soybean. Part 1: 
Evaluation of Three Screening Techniques for Heat and Drought Tolerance. Crop Science, 24, 933-937. https://doi.org/10.2135/cropsci1984.0011183X002400050026x

[16] Rosielle, A.A. and Hamblin, J. (1981) Theoretical Aspects of Selection for Yield in Stress and Non-Stress Environments. Crop Science, 21, 943-946. https://doi.org/10.2135/cropsci1981.0011183X002100060033x

[17] Murray, M.G. and Thompson, W.F. (1980) Rapid Isolation of High Molecular Weight Plant DNA. Nucleic Acids Research, 8, 4321-4325. https://doi.org/10.1093/nar/8.19.4321

[18] Dora, S.A, Mansour, M., Aboulila, A.A. and Abdelwahab, E. (2017) Genetic Diversity and Relationships among Some Barley Genotypes for Net Blotch Disease Resistance Using RAPD, SCoT and SSR Markers. Egyptian Journal of Genetics and Cytology.

[19] Nei, M. and Li, W.H. (1979) Mathematical Model for Studying Genetic Variation in Terms of Restriction Endonucleases. Proceedings of the National Academy of Sciences of the United States of America, 76, 5269-5273. https://doi.org/10.1073/pnas.76.10.5269

[20] Bruckner, P.L. and Frohberg, R.C. (1987) Stress Tolerance and Adaptation in Spring Wheat. Crop Science, 27, 31-36. https://doi.org/10.2135/cropsci1987.0011183X002700010008x

[21] Joshi, P. and Dhawan, V. (2007) Assessment of Genetic Fidelity of Micropropagated Swertia Chirayita Plantlets by ISSR Marker Assay. Biologia Plantarum, 51, 22-26. https://doi.org/10.1007/s10535-007-0005-0

[22] Bhatia, R., Singh, K.P., Jhang, T. and Sharma, T.R. (2008) Assessment of Clonal Fidelity of Micropropagated Gerbera Plants by ISSR Markers. Scientia Horticulturae, 119, 208-211.

[23] Arens, P., Odinot, P., Van Heusden, A.W., Lindhout, P. and Vosman, B. (1995) GATA and GACA Repeats Are Not Evenly Distributed throughout the Tomato Genome. Genome, 38, 84-90. https://doi.org/10.1139/g95-010

[24] Abu Qamar, M., Liu, Z.H., Faris, J.D., Chao, S., Edwards, M.C., Lai, Z., Franckowiak, J.D. and Friesen, T.L. (2008) A Region of Barley Chromosome 6H Harbors Multiple Major Genes Associated with Net Type Net Blotch Resistance. Theoretical and Applied Genetics, 117, 1261-1270. https://doi.org/10.1007/s00122-008-0860-x

[25] Jagadishchandra, K.S. (1975) Recent Studies on Cymbopogon Spreng (Aromatic Grasses) with Special Reference to Indian Taxa: Cultivation and Ecology: A Review. Journal of Plant Physiology, 3, 1-5.

[26] Sharma, J.R., Lal, R.K. and Misra, H.O. (1997) Tripta: A Superior Variety of Palmarosa. FAFAI Journal, 19, 37-44.

[27] Sangwan, R.S., Farooqi, A.H.A., Bansal, R.P. and Sangwan, N.S. (1993) Interspecific Variation in Physiological and Metabolic Responses of Five Cymbopogon Species to Water Stress. Journal of Plant Physiology, 142, 618-622.

[28] Shasany, A.K., Lal, R.K., Patra, N.K., Darokar, M.P., Garg, A., Kumar, S. and Khanuja, S.P.S. (2000) Phenotypic and RAPD Diversity among Cymbopogon Winterianus Jowitt Accessions in Relation to Cymbopogon Nardus Rendle. Genetic Resources and Crop Evolution, 47, 553-559. https://doi.org/10.1023/A:1008712604390

[29] Loarce, Y., Gallego, R. and Ferrer, E. (1996) A comparative Analysis of Genetic Relationships between Rye Cultivars Using RFLP and RAPD Markers. Euphytica, 88, 107-115. https://doi.org/10.1007/BF00032441

[30] Vijayan, K. and Tsou, C.H. (2010) DNA Barcoding in Plants: Taxonomy in a New Perspective. Current Science, 99, 1530-1541. 
[31] Adhikari, S., Saha, S., Bandyopadhyay, T.K. and Ghosh, P. (2015) Efficiency of ISSR Marker for Characterization of Cymbopogon Germplasms and Their Suitability in Molecular Barcoding. Plant Systematics and Evolution, 301, 439-450.

https://doi.org/10.1007/s00606-014-1084-y

\section{Scientific Research Publishing}

Submit or recommend next manuscript to SCIRP and we will provide best service for you:

Accepting pre-submission inquiries through Email, Facebook, LinkedIn, Twitter, etc. A wide selection of journals (inclusive of 9 subjects, more than 200 journals) Providing 24-hour high-quality service User-friendly online submission system Fair and swift peer-review system Efficient typesetting and proofreading procedure Display of the result of downloads and visits, as well as the number of cited articles Maximum dissemination of your research work

Submit your manuscript at: http://papersubmission.scirp.org/ Or contact ajmb@scirp.org 